\title{
Complete intracranial migration of ventriculoperitoneal shunt: a common procedure with a rare complication
}

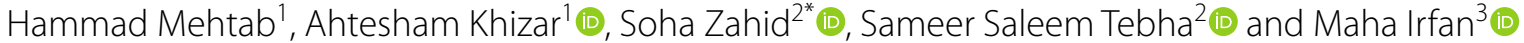

\begin{abstract}
Background: Ventriculoperitoneal shunt insertion is widely used in the treatment of different kinds of hydrocephalus. Shunt failure is one of the most common complications; however complete intracranial shunt migration is rarely reported.

Case presentation: We report a case of an eleven-month-old girl with complete intracranial migration of Ventriculoperitoneal Shunt (Chhabra Shunt). We removed this intracranially migrated shunt with the help of an endoscope (GAAB) and inserted a new Ventriculoperitoneal Shunt (Medtronic Shunt) on the opposite side. She had a good clinical outcome.

Conclusion: Complete intracranial shunt migration is an extremely rare complication. It is likely due to raised intraperitoneal pressure, strong head movements, and inadequate shunt fixation. The best possible approach to prevent shunt migration would be better patient handling along with appropriate operative techniques.
\end{abstract}

Keywords: Intracranial migration, Ventriculoperitoneal shunt, Shunt complication

\section{Background}

Ventriculoperitoneal (VP) shunt insertion is one of the most frequently done procedures in neurosurgery, and it is frequently used to treat different types of hydrocephalus, such as communicating, non-communicating and normal pressure hydrocephalus (NPH). In 1908, the first surgical procedure for VP shunt in long-term treatment of hydrocephalus was performed by Kausch [1].

In $40-70 \%$ of the cases, shunt failure is the most recurring complication [2]. Other complications may include blockage, infection and visual field defects. It can also possibly migrate to other parts of the body, such as gallbladder, anus, liver, umbilicus, colon and thorax; however complete migration of VP shunt intracranially is rarely reported [2]. This complication can be restricted by the firm anchoring of connector sites to the periosteum while

\footnotetext{
*Correspondence: soha.xahid@gmail.com

2 Jinnah Medical and Dental College, Karachi, Pakistan

Full list of author information is available at the end of the article
}

avoiding the large dural opening and large burr holes [3]. $\mathrm{CT}$ and X-ray skull are the investigations of choice in such cases.

\section{Case presentation}

An 11-month-old girl presented to our pediatric emergency department with the history of progressive enlargement of head, multiple episodes of vomiting and decreased oral intake for 10 days. Previously, she was diagnosed with congenital hydrocephalus at the age of one month and underwent medium pressure ventriculoperitoneal shunt (Chhabra Shunt) at some other hospital in the country. Following VP Shunt Surgery, she remained well. On clinical examination, she had enlarged head with tense and bulging anterior fontanelle. Engorged scalp veins were prominent. Sun set sign was present. Shunt chamber could not be palpated throughout the entire course of the shunt. Routine investigations were normal. X-Ray Shunt Series showed an abnormal 


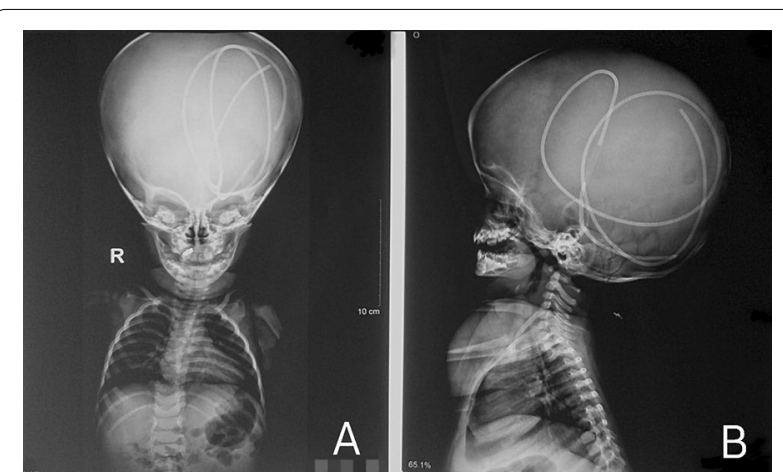

Fig. 1 a, b, X-ray skull AP and lateral views showing complete intracranial migration of ventriculoperitoneal shunt

cranial migration of VP shunt assembly with shunt chamber lying inside the cranium (Fig. 1a, b). CT Brain Plain showed grossly dilated ventricles and VP shunt assembly could be seen inside the ventricles (Fig. 2). At surgery, the previous burr hole site was explored. Burr hole was about $1 \times 1 \mathrm{~cm}$ in size. A rigid pediatric neuro-endoscope (GAAB) was introduced through the burr hole and the entire shunt could be seen coiled up inside the ventricle. It was removed with the help of an endoscopic grasper. A new VP shunt (Medtronic Shunt) was inserted on the opposite side. She had good postoperative recovery, improved clinically and got discharged in three days.

\section{Discussion}

Complete intracranial migration of ventriculoperitoneal shunt is an extremely rare complication of a very common procedure in pediatric patients with hydrocephalus. The incidence of complete upward migration of VP is reported to be around $0.1-0.5 \%$ [4]. After a thorough review of the literature, we found twenty-five cases up to date of total intracranial VP shunt migration [Table 1] [2, 3, 9-13]. Etiology of this complication is unknown, but several factors are thought to be responsible in facilitating proximal shunt migration. It is seen that pediatric patients are more at risk due to the shorter distance between the peritoneum and cranium. This short distance and violent, uncontrolled movements of the head could lead to mechanical displacement of the shunt [3]. Another possible mechanism of proximal shunt migration may be due to inadequate fixation of shunt at the distal end or detachment due to an increased rate of growth in early stages of life [5, 6]. In addition, thin cerebral mantle, large ventricles and wide fontanelles in these infants create an intracranial pressure close to the atmospheric pressure and abdominal pressure remains positive in comparison to the atmosphere. This creates a pressure gradient which would lead to sucking of the shunt towards the cranium [3]. Interestingly, many other case studies report similar patient-related factors, such as malnutrition, young age, thin cortical layer, and severe hydrocephalus which could all be related to upward shunt migration $[3,5-7]$. In most VP shunts insertions, a burr hole is made in the occiput providing a straight path up from the peritoneum [8]. Although this may be the easiest mode of insertion, it may contribute to cranial shunt migration as the path is simply too straightforward.

\section{Conclusion}

Complete intracranial migration of VP shunts is a rare but serious complication in patients with severe hydrocephalus. The best possible approach to prevent migration would be better anchorage of the shunt to the pericranium and peritoneum, a frontal burr hole instead of occipital, and a smaller burr-hole opening. In addition, regular follow ups and educating parents regarding red flags and complications should be readily practiced. Although VP shunts migration is a serious complication, it is not usually fatal. We recommend a nation-wide assessment of the prevalence, incidence and associating risk factors for VP shunt migration to guide future therapeutic practices. 


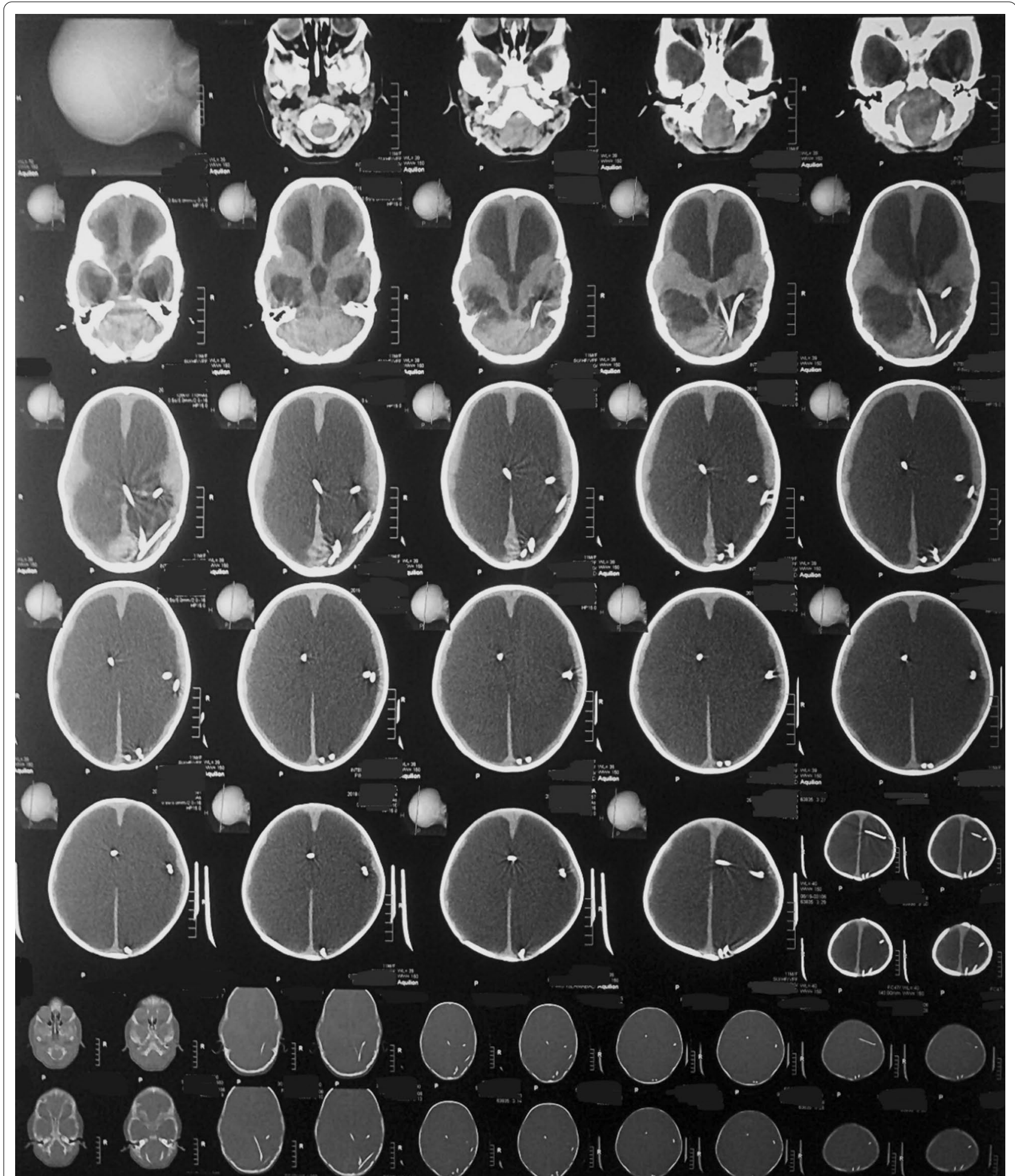

Fig. 2 CT scan brain plain showing gross hydrocephalus along with intracranial migration of ventriculoperitoneal shunt 
Table 1 On review of literature, we found twenty-five reported cases of intracranial migration of ventriculoperitoneal shunt

\begin{tabular}{llll}
\hline & Author's name & Year reported & $\begin{array}{l}\text { No. of cases } \\
\text { reported }\end{array}$ \\
\hline 1 & Mori k & 1975 & 1 \\
2 & Gariejo JA & 1979 & 1 \\
3 & Villarejo F & 1979 & 1 \\
4 & Drigo G & 1983 & 2 \\
5 & Young HA & 1983 & 2 \\
6 & Abou el Nasr HT & 1998 & 1 \\
7 & Eljamel MS & 1995 & 1 \\
8 & Gupta PK & 1999 & 1 \\
9 & C J Dominguez & 2000 & 1 \\
10 & Acharya R & 2002 & 1 \\
11 & Shimzu & 2002 & 1 \\
12 & C. Pereira & 2004 & 1 \\
13 & Trimurti D. Nadkarni & 2005 & 1 \\
14 & Nadkarni TD & 2007 & 1 \\
15 & Oluwole KE & 2007 & 1 \\
16 & Ali MN & 2008 & 1 \\
17 & Aggarwaal A & 2008 & 1 \\
18 & Shahram Shahsavaran & 2011 & 2 \\
19 & Vikas Naik & 2012 & 1 \\
20 & Rakesh Kumar Sharma & 2015 & 1 \\
21 & Elif Basaran Gundogdu & 2017 & 1 \\
22 & Rajendra Shrestha & 2018 & 1 \\
\hline & & & 1 \\
\hline
\end{tabular}

\section{Abbreviations}

VP: Ventriculoperitoneal; CT: Computed tomography; CSF: Cerebrospinal fluid; $\mathrm{NPH}$ : Normal pressure hydrocephalus.

\section{Acknowledgements}

Not applicable.

\section{Authors' contributions}

AK, SZ, SST, MI wrote the manuscript. HM and AK were involved in the management of the patient. All authors read and approved the final manuscript.

\section{Funding}

No funding was required for this work.

\section{Availability of data and materials}

All data are within the article.

\section{Declarations}

Ethics approval and consent to participate Not applicable.

\section{Consent for publication}

Written informed consent was taken from the father of the child for publication of this case report and accompanying images.

\section{Competing interests}

The authors declare that they have no competing interests.

\section{Author details}

${ }^{1}$ Pakistan Institute of Medical Sciences, Islamabad, Pakistan. ${ }^{2}$ Jinnah Medical and Dental College, Karachi, Pakistan. ${ }^{3}$ University College Cork, Cork City, Ireland.

Received: 28 March 2021 Accepted: 18 July 2021

Published online: 22 November 2021

\section{References:}

1. Surchev J, Georgiev K, Enchev Y, Avramov R. Extremely rare complications in cerebrospinal fluid shunt operations. J Neurosurg Sci. 2002;46(2):100-2 (discussion 103)

2. Nejat F, Shahsavaran S, El Khashab M, Keikhosravi E, Kermani H. Ventriculoperitoneal shunt migration and coiling: a report of two cases. J Pediatr Neurosci. 2012;7(2):114.

3. Nadkarni T, Menon R, Dange N, Desai K, Goel A. Cranial migration of complete ventriculo-peritoneal shunt assembly. J Clin Neurosci. 2007;14(1):92-4

4. Sharma RK, Bansal M, Agrawal M, Gupta A, Sinha V. Complete intracranial migration of a ventriculoperitoneal shunt: rare complication of a common procedure. Neurol India. 2015;63:106-7.

5. Mori K, Yamashita J, Handa H. "Missing tube" of peritoneal shunt: migration of the whole system into ventricle. Surg Neurol. 1975;4(1):57-9.

6. Young HA, Robb PJ, Hardy DG. Complete migration of ventriculoperitoneal shunt into the ventricle: report of two cases. Neurosurgery. 1983;12(4):469-71. https://doi.org/10.1227/00006123-19830 4000-00019.

7. Shrestha R, Pradhan R, Pradhan MM. Intracranial migration of proximal and distal components of ventriculoperitoneal shunt in the child. World J Surg Surg Res. 2018;1:1038.

8. Ammar A, Nasser M. Intraventricular migration of VP shunt. Neurosurg Rev. 1995;18(4):293-5.

9. Dominguez C, Tyagi A, Hall G, Timothy J, Chumas P. Sub-galeal coiling of the proximal and distal components of a ventriculo-peritoneal shunt an unusual complication and proposed mechanism. Child's Nerv Syst. 2000;16(8):493-5.

10. Agrawal M, Bansal M, Gupta A, Sharma R, Sinha V. Complete intracranial migration of a ventriculoperitoneal shunt: rare complication of a common procedure. Neurol India. 2015;63(1):106.

11. Malhotra A, Malhotra M. Ventricular migration of shunt: Chhabra shunt complication. Int Surg J. 2015;2:706-9.

12. Naik V, Phalak M, Chandra P. Total intracranial shunt migration. J Neurosci Rural Pract. 2013;04(01):95-6.

13. Gundogdu EB, Ozsoy U, Tuzun Y. Complete intraventricular migration of the ventriculoperitoneal shunt. Eur Res J. 2017;3:87-9.

\section{Publisher's Note}

Springer Nature remains neutral with regard to jurisdictional claims in published maps and institutional affiliations. 